\title{
Combustível da fé: mudança socioeconômica e rearranjo religioso em Macaé - RJ
}

\author{
Faith fuel: social-economical change and religious reorganization in Macae, \\ RJ
}

\author{
Leonardo Gonçalves de Alvarenga * \\ Fabio Py Murta de Almeida **
}

\begin{abstract}
Resumo
Este artigo tem como objetivo analisar as mudanças socioeconômicas ocorridas na cidade de Macaé a partir de 1980 e seus efeitos sobre o campo religioso, com foco nos evangélicos e nos sem-religião. A metodologia lança mão de dados quantitativos do IBGE e procura analisar esses dados para ultrapassar uma leitura superficial e avançar na análise desse campo religioso complexo, que está diretamente relacionada à chegada da Petrobras na cidade de Macaé, inaugurando uma nova era na região, com a injeção de capital na cidade. Nesse sentido, percebe-se o desenvolvimento urbano na região ocorreu sob o impacto da multinacional Petrobras, ocasionando a criação de diferentes mercados e oportunidades de investimentos, fazendo com que as instâncias religiosas fossem reorganizadas em uma nova configuração do campo religioso macaense. Para tal argumentação nos basearemos no pensamento social de Danièle Hervieu-Léger, quando reconhece que a modernidade e a urbanização se relacionam diretamente com as mudanças e as novas modulações sociorreligiosas.
\end{abstract}

Palavras-chave: impactos; petróleo; religião; pluralismo religioso; evangélicos.

\begin{abstract}
This article aims to analyze the social-economical changes which took place in Macae after 1980 and their effects on religious field, focusing in Evangelical and Non-religious people. The methodology uses quantitative data from IBGE and intends to analyze these data to exceed a superficial reading and advance on the depth of the complex religious field which is directly related to the arrival of Petrobras in town. On this sense, the urban development which took place due to multinational Petrobras impact, in Macae region, causing the creation of different markets, investment opportunities, making religious organizations remodel on a new setting in Macae's religious field. To reach such goal, we base our analysis on Daniele Hervieu-Leger's social thought, when she recognizes that modernity and urbanization are directly related with new social-religious changes and social-religious modulations.
\end{abstract}

Keywords: impact; petroleum; religion; religious pluralism; evangelicals

\footnotetext{
Artigo submetido em 03 de março de 2018 e aprovado em 29 de abril de 2019.

* Doutor em Ciência da Religião pela PUC-SP. Bolsista Recém-Doutor no Programa de Pós-Graduação em Políticas Sociais da UENF. País de origem: Brasil. E-mail: alvarengalg2@gmail.com

** Doutor em Teologia pela Pontifícia Universidade Católica do Rio de Janeiro. Professor do Programa de Pós-Graduação em Políticas Sociais da UENF. País de origem: Brasil. E-mail: pymurta@gmail.com
} 


\section{Introdução}

A série histórica dos censos de religião do IBGE, de 1980 a 2010, apresenta um quadro de profundas mudanças no campo religioso no Brasil, como foi analisado por Regina Novaes (2004), Ari Pedro Oro (2003), Antônio Flávio Pierucci (2004) e Leonildo Campos (2013, p. 231-234). Tal como destaca Leonildo Campos (2013), o Sudeste foi a região que mais sentiu os efeitos dessas mudanças. No artigo, veremos o caso de uma cidade do norte do estado do Rio de Janeiro, Macaé, destacando dentre os grupos religiosos existentes, os evangélicos. Entendemos que tais grupos, longe de serem um bloco monolítico, mostram-se complexos e heterogêneos, dado que nos últimos anos tem despertado a atenção de muitos pesquisadores (CAMPOS, 2013, p. 232-234, ALVARENGA, 2017; PY, 2016a). Também se dará atenção aos sem-religião, que representam um cenário religioso menos institucional e mais privado, cujos números ultrapassam todos os demais grupos religiosamente institucionalizados (NOVAES, 2004). Nossa tese é a de que a maioria dos grupos tradicionais cresceram paralelamente ao crescimento da cidade, mas nada comparado aos pentecostais que, atingiram um percentual elevado, perdendo somente para os "sem-religião". Atrelado à tese, percebe-se que no grupo classificado como tradicional, os batistas foram os que até, o ano 2000, mais cresceram sobre os impactos trazidos à nova sociedade macaense, quiçá no Brasil, com uma taxa de crescimento considerável e atípica entre 1980 e 2000, de 2,5\% para 9,5\% (IBGE, 1980 a 2010) (ALVARENGA, 2017).

O protestantismo histórico (CAMPOS, 2013, p. 232-234; PY, 2016a) desacelera em seu crescimento e o declínio acontece à medida que outros grupos crescem como os pentecostais e os sem-religião. Os pentecostais saltaram de 3,23 \% da população para 17,22\% (IBGE, 1980 a 2010) (ALVARENGA, 2017, p. 121-134). Todos esses números acompanham a taxa de crescimento da população local, sob o impacto da industrialização. Se esses impactos beneficiaram numericamente os pentecostais, outros grupos que outrora eram majoritários, como os católicos, ficaram para trás com uma taxa de crescimento menor. Estes eram $74 \%$ da população no censo de 1980 e de acordo com o último censo (2010) não passaram 
de 40\% em Macaé (ALVARENGA, 2017). Então, nesse texto, analisaremos esses números à luz das transformações socioeconômicas ocorridas na antiga "Vila de pescadores" que em curto espaço de tempo passou ao status de "Capital Nacional do Petróleo", com a chegada da multinacional Petrobrás, atraindo investidores do país e do exterior, além da população em busca de emprego e estabilidade (PIQUET, 2010, p. 11-18). Uma das hipóteses para o crescimento de determinados grupos e baixa no crescimento de outros é a migração, a inflexibilidade, a falta de diálogo e a capacidade de reinvenção frente a disputa pelo capital simbólico ${ }^{1}$ plural e local, e as novas modalidades de crer (HERVIEU-LÉGER, 2005; 2008).

Reiteramos, portanto, que a leitura dos dados dos Censos e, sobretudo da dinâmica interna das referidas religiões, se recorrerá ao pensamento de Danièle Hervieu-Léger (2000; 2005; 2008) sobre as mudanças das religiões na modernidade em meio às suas transformações. Sua análise da religião, embora embasada no contexto europeu, possui aproximações que ajudam na elucidação de certos cenários latino-americanos, especificamente no Brasil (ALVARENGA; SENA, 2016). Também, as construções, em termos de representações e de práticas do vínculo comunitário localizado, no qual, a pertença à linhagem religiosa se atualiza (HERVIEU-LÉGER, 2000, p. 50-51). Neste sentido, o foco será sobre o aprofundamento da industrialização em Macaé e perceber a dinamicidade da religião (ALVARENGA, 2017) nos urbanismos efervescentes reconhecendo os impactos trazidos, sobretudo na relação dos indivíduos com as tradições religiosas (HERVIEU-LÉGER, 2008), que, por sua vez entende-se que tenha implicação nas amostras censitárias. No lastro do pensamento hervieu-legeriano, a religião, que outrora detinha maior poder de transmissão e perpetuação da memória de um acontecimento fundador original através de uma linha de crença e regulava a crença e o comportamento dos fiéis, fica para trás e agora possui muito mais um caráter subjetivo, baseado nas opções pessoais dos indivíduos que dela se servem.

\footnotetext{
${ }^{1}$ Segue-se a definição de capital simbólico de Pierre Bordieu: “O capital simbólico - outro nome da distinção - não é outra coisa senão o capital, qualquer que seja a sua espécie, quando percebido por um agente dotado de categorias de percepção resultantes da incorporação da estrutura da sua distribuição, quer dizer, quando conhecido e reconhecido como algo de óbvio" (BORDIEU, 2003, p. 145). Ainda que seja consequente de poder simbólico, esse que seria "um poder que aquele que lhe está sujeito dá àquele que o exerce, um crédito com que ele o credita, um fide, uma auctoritas, que lhe confia pondo nele a sua confiança. É um poder que existe porque aquele que lhe está sujeito crê que ele existe" (BORDIEU, 2003, p. 177).
} 
Hervieu-Léger (2005) está entre os revisionistas do conceito de secularização. Para autora os grupos religiosos tradicionais estão submetidos à instantaneização e pulverização da memória coletiva. Ao invés de se reconhecerem em uma tradição fixa, de uma continuidade entre o passado e o presente, estes indivíduos fazem bricolagens e fazem tradição (HERVIEU-LÉGER, 2005). O sentimento de pertença tende a desparecer. Crer e pertencer eram coisas inseparáveis, hoje é diferente: "Ser religioso na modernidade, não é tanto saber-se engendrado, mas querer-se engendrado" (GISEL apud CAMURÇA, 2003, p. 254).

Hervieu-Léger propõe uma nova categoria para explicar essa mudança, a religião pós-tradicional (2005), que tem na escolha a base fundamental para adesão religiosa. As opções pessoais dos indivíduos ficam em evidência e o determinismo da tradição perde a vez para iniciativa e criação dos indivíduos, criando assim uma religião "a minha maneira" (CHAMPION, 1990). Esse desencantamento com a tradição não decreta o fim da religião, muito menos das instituições tradicionais (HERVIEU-LÉGER, 2005). Antes, o que acontece é um "remanejamento radical na relação do indivíduo com a tradição, que se abre a possibilidades ilimitadas de bricolagem, invenção e manipulação do indivíduo nos dispositivos de sentido suscetíveis a fazer tradição” (HERVIEU-LÉGER, 2005; 2008).

\section{Transformações no campo religioso macaense}

As transformações locais que dizem respeito ao campo religioso em Macaé tanto se devem às mudanças que ocorreram no contexto local (socioeconômicas), quanto ao contexto nacional de reordenamento das religiões na contemporaneidade (SWATOWISKI, 2009; ALVARENGA, 2017). Nesse período, a pluralização e diversificação religiosa trouxeram novos ares para a cidade, que "não pode ser vista separada da heterogeneização da população local e a diversificação cultural, decorrente principalmente da intensa migração” (SWATOWISKI, 2009, p. 58). Se antes prevalecia uma hegemonia das igrejas tradicionais (católicas e 
protestantes), nas duas primeiras décadas que sucedem a instalação da Petrobras em Macaé, essa realidade sofre os primeiros impactos, como apontam dados do IBGE (1980 a 2010) na tabela abaixo:

Tabela 1 - Transformações no campo religioso macaense

\begin{tabular}{|l|l|l|l|l|l|}
\hline & Católicos & Evangélicos & Ev. De Missão & Pentecostais & Sem-religião \\
\hline 1980 & 75,0 & 11,0 & 8,0 & 3,0 & 8,0 \\
\hline 1991 & 63,0 & 19,0 & 12,0 & 7,0 & 16,0 \\
\hline 2000 & 51,0 & 22,0 & 12,0 & 11,0 & 17,0 \\
\hline 2010 & 40,0 & 34,0 & 8,2 & 17,2 & 19,0 \\
\hline
\end{tabular}

Fonte: IBGE - Censos Demográficos 1980, 1991, 2000 e 2010.

O número de protestantes tradicionais (12\% da população evangélica) tinha entre os batistas a maior representação na cidade: 70\%. No entanto, o Censo mostra que esse número sofreu uma estagnação de 1991 a 2000, enquanto os semreligião cresceram significativamente no período que sucede a Petrobrás - entre 1980 e 1991, tendo um salto de $8 \%$ para 16\% da população, além dos pentecostais que cresceram de 3\% para 11\% (SWATOWISKI, 2009; ALVARENGA, 2017).

A migração em decorrência dos meios de produção é um fator importante para entender as mudanças que ocorreram no cenário religioso em Macaé por causa da instalação das indústrias petrolíferas e possíveis mudanças no perfil das igrejas batistas especificamente (ALVARENGA, 2017). Para a mudança do perfil religioso das geografias, o antropólogo canadense Peter Beyer (1998, p. 56), aborda tais transformações no âmbito "das culturas, dentre elas as que recebem um grande volume de migrantes, argumenta que as religiões estão longe de dar continuidade aos seus processos de integração"; ao contrário, a migração tem agido no sentido de redefinir as religiões, como espaço privilegiado de construção da religião do migrante. Outro importante autor que defende a hipótese de que não só a migração pode contribuir para mudanças no perfil religioso quanto também pode influenciar no seu crescimento é Jean-Pierre Bastian (1994). Para Bastian, a migração (mais especificamente interna) é um dos fatores que contribuíram para numerosas 
mutações religiosas ${ }^{2}$ na América Latina como um todo "esse movimento migratório se deu em especial de 1930 a 1960" (Tradução nossa, BASTIAN, 1994, p. 73).

\section{Migração e perfil religioso: indícios de mudanças?}

No campo religioso (BOURDIEU, 2003), a migração pode ser um fator de grande relevância para algumas religiões, se não para todas elas (BASTIAN, 1994, p. 78-82). Peter Beyer (1998) trabalha com a hipótese de que as consequências da migração ajudem a (re) definir as religiões em todas as áreas onde elas estejam representadas. A migração, como parte integrante do processo de globalização, tanto pode dificultar e "punir" formas religiosas como favorecer e "premiar" a expansão de determinadas propostas religiosas mais adaptadas (MOREIRA, 2008). Bastian destaca no sentido macro o que, para a análise do caso específico de Macaé, será de grande valia:

uma certa homogeneidade anterior foi substituída por uma diferenciação acelerada entre ricos e pobres em uma região de vocação agrícola que, até então, antes vivia sob o modelo tradicional de integração social, daquele de uma comunidade rural homogênea e corporativa. (BASTIAN, 1994, p. 203, tradução nossa).

O movimento que se intensifica de mudanças ou do que também poderia chamar de "êxodo rural" em direção à cidade e à vida urbana traz consigo novas demandas de sentido frente às ofertas de trabalho e expectativas de vida da população migrante (MOREIRA, 2008). O objetivo neste tópico é ter, a partir especialmente dos microdados dos Censos de 2000 e 2010 (período de maior mudança em Macaé), uma noção a respeito não só do perfil sociorreligioso dos migrantes, mas também um conhecimento acerca de quais grupos religiosos receberam um maior volume migratório e seu perfil socioeconômico (MARTINE, 2005). Com isso, será possível conjecturar quanto às mudanças ocorridas face ao fluxo migratório e as possíveis demandas de sentido que trouxeram consequências

\footnotetext{
${ }^{2}$ Para falar de mutações religiosas, Bastian (1994, p. 202) recorre à noção de Roger Bastide a respeito: "a transição de uma estrutura a uma interrupção de sistemas", culminando no surgimento de novos movimentos religiosos. Portanto, não são contempladas pelo autor mudanças que ocorrem dentro de uma estrutura, as quais buscarei também analisar neste trabalho.
} 
e redefinições, sobretudo nas igrejas batistas (ALVARENGA, 2017). Na virada do milênio foi de uma mudança radical na população macaense, contando com o movimento de migrantes. Um aumento proporcional ao número de habitantes de 7,28\%. Reconhece-se que o aumento da população somado ao movimento migratório e à falta de oportunidades contribuiu para o aumento das desigualdades sociais na cidade, trazendo, assim, não só aos órgãos públicos, mas (conjecturando) também às religiões anfitriãs, novas "demandas de sentido" que exigiram, consequentemente, novas posturas (ALVARENGA, 2017). Para aquelas religiões que se fecharam ou simplesmente caíram no ostracismo ou falta de diálogo, houve certamente um declínio numérico. Sobre esse movimento de declínio face às novas demandas da sociedade, Leonildo Campos diz que: "não é impossível prognosticar que a opção pentecostal, neopentecostal e carismática continue a minar as instituições religiosas tradicionais que institucionalizaram as fórmulas de se resolver os problemas das massas" (CAMPOS, 2013, p. 45).

Essa análise de Campos (2013) é fundamental para compreendermos a relação entre as mudanças sociais e o crescimento das igrejas pentecostais e o estacionamento da grande maioria das igrejas tradicionais. Atrelado às desigualdades sociais presentes nesse contexto sobre o qual se dá o movimento migratório está o forte índice de violência e os casos de mortalidade em decorrência dela (HARVEY, 2005). Os estudos do Mapa da Violência, que começaram em 2007, apontavam Macaé como o quinto município mais violento do país em homicídios entre jovens de 15 a 24 anos de idade (BRISO, 2012). Um índice extremamente alto para uma cidade deste porte. Na matéria publicada pela revista Veja, no ano de 2012, de Caio Barretto Briso, intitulada "A maldição do petróleo"3, foram colhidos alguns dados que só reforçam o quanto a sociedade foi impactada e de um ponto de vista negativo pelo processo acelerado de urbanização em decorrência da indústria petrolífera (ALVARENGA, 2017). Os números que a cidade apresentava eram extremos tanto na área econômica quanto nas de segurança pública e saúde: 51\% era a taxa de homicídios por 100 ooo habitantes, uma das maiores do estado e

\footnotetext{
${ }^{3}$ Os impactos do petróleo na região podem ser consultados em Herculano (2013).
} 
mais que o dobro da taxa da capital; 56\% foi o aumento populacional em 10 anos (PIQUET, 2010, p. 14-17). Teve a quinta parte de seus habitantes em favelas, uma exceção fora da capital (PIQUET, 2010, p. 18).

Não é o caso de estabelecer uma relação de causa e efeito sobre os problemas sociais mencionados e o movimento migratório; porém, como parte desse crescimento explosivo de Macaé, não é uma tarefa fácil separar as duas coisas, seja pela falta de oportunidades, seja pelo atrativo econômico que a cidade passou a oferecer (ALVARENGA, 2017). A mobilidade tornou-se um modus vivendi. A partir da sociologia da religião de Daniele Hervieu-Léger (2008) entende-se que o sujeito que migra em busca de realização dificilmente renuncia à dimensão religiosa, mas a molda a partir da interação constante com uma pluralidade de ofertas simbólicas que, de alguma maneira, devem responder a seus desafios existenciais (MARINUCCI, 2011).

Segundo Araújo, após sua análise do censo demográfico de 2000, chega-se à conclusão de que "Macaé sofre um nítido processo de segregação espacial entre pobres e ricos, que se reflete de maneira especial na população migrante" (ARAÚJO, 2005, p. 9). Em algumas regiões periféricas, existe uma pequena quantidade de migrantes com rendas muito elevadas, que podem ser explicadas pela ligação destes com o ramo petrolífero, afirma Araújo (2005). Os apelos, através de compensações financeiras, que chegam ao dobro da renda normal, são tão eficazes, que muitos ficam 30 dias (ou mais) longe da família, em alto mar. Um ambiente de confinamento propício a mal-estares, tristezas e desânimos, afeções orgânicas, depressão, estresse, transtornos, entre outros, e podem manifestar-se em decorrência da exposição a riscos do ambiente de trabalho e dos elementos da organização do trabalho (LEÃO; GOMEZ, 2014).

Diante dessas informações, faz-se necessário, até mesmo pela ênfase do discurso religioso que se apoia numa ideia da transformação, perguntar-se sobre a relação entre o movimento migratório e a religião. O perfil socioeconômico dos diferentes grupos religiosos presentes na cidade de Macaé e o quanto cada um teve 
(se mais ou menos) concentração de migrantes (ALVARENGA, 2017). Este mapeamento tem como objetivo suscitar questões, e até mesmo novas leituras, tais como as dimensões descobertas pelas entrevistas feitas por Marinucci (2011) a respeito das transformações ocorridas na vida de fé dos migrantes após a migração. Essas dimensões são: emergencial (transitar como resposta a situações de crise); relacional (transitar em busca de redes sociais de apoio e solidariedade); doutrinal (transitar por divergências doutrinais e busca de sentido); de alteridade (a diversidade pastoral e o pluralismo religioso); pragmática (os problemas práticos do dia-a-dia) e autorrealização (MARINUCCI, 2011).

\section{Números de migrantes por religião em Macaé e suas condições socioeconômicas}

Seguem, abaixo, dados que mostram a presença de migrantes entre os grupos batistas, pentecostais, católicos e os sem-religião. O critério usado para a escolha desses grupos se deve a maior concorrência religiosa entre eles.

\subsection{Batistas}

Em 2010, enquanto o percentual de religiosos que se diziam batistas teve uma leve queda, o percentual de migrantes batistas, que era de praticamente 39\%, foi para quase 43\%. Ao levar em consideração a análise de Silva e Faria (2016), estes dados indicam que de 2000 a 2010, quando o número de migrante cresceu na ordem de $63 \%$, ou seja, o equivalente a 74.000 habitantes, nesse período as igrejas batistas experimentaram um crescimento de 4,16\% do percentual de migrantes. Por outro lado, o número de sujeitos declarantes da fé batista teve uma constante de declive. O estado do Rio de Janeiro como um todo foi onde houve, além de uma desaceleração, um leve declínio (ALVARENGA, 2017). 
As áreas de ponderação 4 com maior presença de batistas, na área urbana, são as áreas periféricas de classe média e média baixa (ALVARENGA, 2017). São bairros antigos da cidade e muito populosos além da zona rural, com números de habitantes muito baixo, de $\mathbf{1 4 . 1 1 2}$ habitantes, com a maior extensão geográfica (ALVARENGA, 2017). Os batistas também possuem uma presença representativa em áreas em expansão (CADENA; COSTA, 2012) e com grande volume populacional como os bairros do Lagomar e Parque Aeroporto.

Portanto, se quisermos saber onde estão os batistas, a partir desses primeiros dados, podemos afirmar que estão sobremaneira inseridos entre o centro e a periferia. Nas regiões onde houve maior expansão urbana em Macaé, os batistas cresceram mais nas regiões de periferia e proporcionalmente na zona rural (ALVARENGA, 2017). Estes dados são importantes para até mesmo confirmar o que disse Mendonça (2002, p. 44): "embora as igrejas batistas tenham uma abrangência de profundidade popular maior que as demais igrejas de origem missionária, não se pode dizer que sejam Igrejas populares”. Portanto, os batistas em Macaé têm um perfil centro-periférico. Esse perfil equilibrado e paradoxal (centro-periférico) não estaria desafiando a estabilidade de uma linhagem religiosa integrada? Hervieu-Léger (2000) apresenta algumas hipóteses que ainda precisam ser testadas. Nas trajetórias de identidade religiosa, ocorrem elementos determinantes como o regime de espacialidade onde acontece uma construção (em termos de representações e de práticas) do vínculo comunitário localizado, no qual a pertença à linhagem religiosa se atualiza sob os signos da mobilidade e desterritorialização. $\mathrm{O}$ que acontece seria uma dupla valorização de uma ordem e da figura móbil do peregrino, que se experimenta principalmente nos novos grupos religiosos (HERVIEU-LÉGER, 2000). Essa reorganização da dialética da tradição e do movimento no espaço religioso intervém ao mesmo tempo se redefine a polarização espacial característica das organizações religiosas do campo cristão,

\footnotetext{
${ }^{4}$ O município de Macaé foi dividido no censo demográfico de 2010 em 12 áreas de Ponderação (AP), que na época em que Araújo (2005) pesquisou eram apenas 6 (seis - (ALVARENGA, 2017). Essas AP's são agrupamentos de setores censitários e representam o menor recorte espacial com dados da amostra do Censo Demográfico. Dentro de cada Área de Ponderação são encontrados alguns bairros, e os limites das AP's respeitam a divisão administrativa de bairros na maioria dos casos (ARAÚJO, 2005, p. 4).
} 
entre a estabilidade das instituições (estruturas, doutrinas) e a dinâmica móbil dos movimentos missionários em espaços desiguais.

\section{$3.2(\mathrm{Neo})$ pentecostais}

Entre os (neo) pentecostais, a migração acompanhou praticamente em paralelo o crescimento do número de religiosos, chegando a ultrapassá-los em 2010 (ALVARENGA, 2017). Foi relevante o crescimento dos (neo) pentecostais em Macaé, tanto do ponto de vista dos fiéis locais quanto dos migrantes. Faremos a mesma pergunta que fizemos ao analisar os batistas. Onde estão os migrantes (neo) pentecostais e qual sua condição socioeconômica? Os pentecostais concentram-se majoritariamente nas periferias, mas também disputam terreno com os batistas nas áreas onde mais crescem (ALVARENGA, 2017; PY, 2016b; PY; PEDLOWSKI, 2018). O que acontece com os (neo) pentecostais não acontece necessariamente com os batistas. Nem sempre os batistas chegam aonde chegam os (neo) pentecostais, principalmente em números. Por que razão? Os (neo) pentecostais são maioria nas periferias (ROLIM, 1979; JACOB, 2003; FAJARDO, 2011; ALENCAR, 2013; PY, 2016b; PY; PEDLOWSKI, 2018). Se esse segmento está fortemente presente nas periferias, isso significa que os demais segmentos são minorias. As minorias são aquelas cujo regime de verdade, conforme HervieuLéger (2000) é validado por um código de sentido ou sistema normativo imposto em nome da autoridade heterônoma de uma tradição. São os grupos tradicionais, em declínio (PIERUCCI, 2004). Ora, se os grupos tradicionais, cujo regime de verdade é o que apela a uma tradição, seria o caso de pensar que nos grupos (neo) pentecostais experimenta com maior força o efeito de um deslocamento interno do regime de verdade e do regime de autoridade; passa-se das verdades obrigadas e controladas às verdades a serem acreditadas pela valorização da autenticidade pessoal do sujeito religioso e pelas "testemunhas de sentido", na qual a autoridade se impõe aos sujeitos religiosos por meio dos testemunhos que eles dão da autenticidade de suas trajetórias pessoais (HERVIEU-LÉGER, 2000). O que não quer dizer que alguns grupos considerados tradicionais não passem por esse 
processo de deslocamento, como no caso dos batistas (ALVARENGA, 2017). O que acontece é que nestes últimos ainda existe uma tensão forte entre os regimes de verdade validado pela tradição e o validado pelo sujeito religioso (ALVARENGA, 2017).

\subsection{Os sem-religião}

Nesta categoria mostra-se a evolução dos números a partir da década de 80 . O que há de significativo nestes números? Interpretando os dados compreende-se que a cidade de Macaé era menos religiosa no sentido de pertença institucional na década de 70, e esse cenário foi adquirindo um novo aspecto ao longo dos anos (ALVARENGA, 2017). A não filiação religiosa entre os nativos macaenses diminui enquanto os migrantes sem filiação religiosa aumentaram 19\%. O volume de opções religiosas, ou mesmo o crescimento e prosperidade da região parecem ter despertado nos macaenses vínculos com sem-religião.

Percebe-se que onde há maior concentração dos sem-religião, é também onde estão batistas e (neo) pentecostais e onde também está concentrada a maior população de migrantes de baixa renda. Não são necessárias muitas explicações para se perceber que os sem-religião têm uma concentração muito pequena nas áreas onde há uma renda elevada e onde também se concentra o maior número de migrantes internacionais. Sua presença, tanto em relação aos religiosos quanto aos migrantes, está nas áreas com o nível de renda baixo. Estes dados trazem questões ainda pouco exploradas nos estudos sobre os sem-religião (ALVARENGA, 2017). Num primeiro momento, relacionou-se com algumas reflexões feitas por Regina Novaes (2004) sobre esse grupo em ascensão, a fim de estimular as leituras sobre o caso de Macaé-RJ.

Regina Novaes fez algumas considerações esclarecedoras sobre o perfil dos sem-religião. Segundo Novaes (2004), são três as principais mudanças que caracterizam o campo religioso brasileiro: a diminuição percentual de católicos, o crescimento dos evangélicos e o aumento dos "sem-religião" (PIERUCCI, 2004; 
TEIXEIRA; MENEZES, 2013). A autora (NOVAES, 2004) ainda afirma que, enquanto se tem escrito muito sobre os dois primeiros grupos, pouco se tem escrito sobre o terceiro. Pelos recortes que já foram apresentados, não há dúvidas de que esse quadro se aplica às microrregiões, em especial à cidade de Macaé (ALVARENGA, 2017). Apenas um parêntese para o caso dos sem-religião na Europa. Uma importante análise desse fenômeno crescente no cenário europeu é levantada por Danièle Hervieu-Léger (2008, p. 71-72), quando esta observa que uma vez enfraquecida a capacidade reguladora das instituições religiosas, bem como os "processos tradicionais de identificação religiosa, fica muito mais fácil a 'saída da religião"'. Ou tende a ocorrer uma nova escolha religiosa, com base nos recursos que "os indivíduos vão encontrando pelo caminho, ou se engrossa a fila dos que se definem como ‘sem-religião”' (TEIXEIRA, 2008).

O crescente número dos sem-religião (de 8\% em 1980 para 19\% em 2010, conforme (TEIXEIRA; MENEZES, 2013) em Macaé pode ter como causa não só as mudanças demográficas, provocadas pelo intenso processo de urbanização e migração, mas também as desilusões com os valores e normas transmitidos verticalmente, de geração em geração, e com a não concretude dos objetivos ora traçados por melhores condições de vida. Para Daniele Hervieu-Léger (2008, p. 74), os "indivíduos constroem sua própria identidade sociorreligiosa a partir dos diversos recursos simbólicos colocados à sua disposição e/ou aos quais eles podem ter acesso em função das diferentes experiências em que estão implicados”. Uma religião menos institucional está em voga, provocando rupturas e traçando um novo perfil religioso (TEIXEIRA; MENEZES, 2013).

Os sem-religião, em vez de serem confundidos com “ateus” e "agnósticos”, podem ser compreendidos como um retrato de um processo de desencaixe ou desinstitucionalização, sem perda da fé (HERVIEU-LÉGER, 2008). Logo, ser religioso sem religião, segundo Novaes (2004, p. 328), "significa, sobretudo, um certo consumo de bens religiosos sem as clássicas mediações institucionais como um estado provisório (entre adesões) ou como uma alternativa de vida e expressão cultural”. O enfraquecimento dos grupos tradicionais, longe de ser só a perda de 
adeptos ou até mesmo do interesse daqueles que vão para as igrejas (neo) pentecostais, também tem como fator explicativo os sem-religião, que não querem nem uma coisa nem outra, preferindo a saída da religião (institucional). Em certo sentido, eles deixam a religião e guardam a fé (ALVARENGA, 2017).

Por fim, há algo mais que desperta a atenção nessa categoria. Voltemos à camada religiosa dos sem-religião, por meio de seus rendimentos econômicos. Segundo o censo do IBGE de 2010, em que os dados continuam apontando para o crescimento dos sem-religião, vê-se que o rendimento total mediano se encontra em um nível abaixo do que supomos. Segundo o Censo do IBGE de 2010, o total de rendimentos brutos dos sem-religião, em reais, era de $\mathrm{R} \$ 1.554,00$, um pouco acima dos valores de 2000, que era de $\mathrm{R} \$ 1.211$,00 (valores atualizados para 2010). No período que compreende a pesquisa deste censo (a primeira década do século XXI), o salário mínimo foi de 200,00 a 500,00 reais. Sendo assim, o nível de rendimento bruto dos sem-religião ultrapassara um pouco mais a renda mínima, situando-os entre a nova classe média, ou classe $\mathrm{C}$, cuja renda mensal, nessa época, girava em torno de 1.126 reais a 4.854 reais (DA REDAÇÃO VEJA, 2010). Essas informações nos levam a concluir que quem sai da religião institucional não está entre os mais ricos e abastados financeiramente, porque adquiriram uma autonomia financeira, mas os que se encontram nas periferias ${ }^{5}$ por razões diversas. Conservam uma fé que, apesar das dificuldades, mantém-se viva no âmbito pessoal e privado. A trajetória dos sem-religião ao mesmo tempo que tem semelhanças com o movimento (neo) pentecostal, em relação ao deslocamento do regime de verdade, possui uma diferença que é determinante. $\mathrm{O}$ sujeito da experiência não depende necessariamente de estar na igreja ou instituição religiosa.

Em vista disso, esses dados são um forte indicativo para o que HervieuLéger já havia indicado na França (2008): a importância dos sem-religião como um campo e grupo crescendo na classe média da população, que perde (ou minimamente, diminui) o interesse pela filiação religiosa. Essas informações serão

\footnotetext{
${ }^{5}$ Neste caso, o termo periferia não se restringe a apenas uma fatia geográfica do espaço urbano, mas sim a uma condição de vida precária, marcada pela desigualdade social, desprivilegiada em termos de serviços públicos e infraestrutura urbana.
} 
úteis mais adiante, quando trataremos da modernidade religiosa. Uma forma de analisar a religião na modernidade, que tem praticamente seus primeiros trabalhos na Europa (HERVIEU-LÉGER, 2005; 2000), mas que encontra resistência quanto a sua aplicação na América Latina (TEIXEIRA; MENEZES, 2013).

\section{Identidades religiosas fixas ou flutuantes? ${ }^{6}$}

Para Faustino Teixeira (2013, p. 17), faz-se necessário uma pesquisa analítica capaz de "ultrapassar uma leitura superficial dos dados apresentados e avançar na espessura desse campo religioso tão complexo e desafiador que acontece no Brasil”. Os números dos Censos em Macaé nas duas primeiras décadas que sucedem a instalação do polo petrolífero é um forte indicativo "dos impactos das mutações modernas na geografia” (HARVEY, 2005, p. 79) de que o campo religioso local sofreu em decorrência do processo de industrialização. Todavia, faltam interpretações que dê sentido a esses números. Como escreveu Pierre Bourdieu (1963, p. 215), a "estatística é apenas umas das formas de representar a vida social”. A tarefa sociológica ou de sua interpretação, mesmo quando a força da evidência dos números, das tabelas e gráficos parece marcante, é atribuir-lhes sentido que nunca perdem seu caráter hipotético. Para Bourdieu (1963), a explicação sociológica deve funcionar como "costura” produtora de inteligibilidade. Seguiremos adiante na tentativa dessa tarefa.

Segundo David Harvey (2005, p. 103), à medida da expansão e impactos da modernidade industrial foram demandando "novas possibilidades de sociodicéias nos quais foram se modelando, originando novas relações culturais ao longo do século”. Sendo assim, não estariam os novos grupos religiosos e o intenso pluralismo religioso ameaçando às formas de cristalização de universos simbólicos

\footnotetext{
${ }^{6}$ As categorias "fixas" e "flutuantes" foram utilizadas propositalmente como trocadilho em referência a tipos de plataforma localizados na Bacia de Campos. Uma unidade flutuante sofre movimentações devido à ação das ondas, correntes e ventos, com possibilidade de danificar os equipamentos a serem descidos no poço. Por isso, torna-se necessário que ela fique posicionada na superfície do mar, dentro de um círculo com raio de tolerância ditado pelos equipamentos de subsuperfície. As plataformas fixas são projetadas para receber todos os equipamentos de perfuração, estocagem de materiais, alojamento de pessoal, bem como todas as instalações necessárias para a produção dos poços. Não tem capacidade de estocagem de petróleo ou gás, tendo o mesmo que ser enviado para a terra através de oleodutos e gasodutos. Disponível em: <https://petrogasnews.wordpress.com/2011/03/06/tipos-de-plataformas-depetroleo/>.
} 
dos grupos tradicionais? Muitos teóricos (HERVIEU-LÉGER, 2005; 2008; CAMURÇA, 2003) têm se perguntado sobre o futuro dos grupos tradicionais nesse novo cenário de efervescência religiosa, tanto no Brasil quanto em outros continentes, como o europeu.

No campo religioso norte-fluminense, iniciou-se um processo de pluralização, concorrência, disputa e diversidade religiosa muito grande se comparada às décadas anteriores (ALVARENGA, 2017). Diante disso, suscita a pergunta se as identidades individuais e coletivas seriam fortemente afetadas ou não, uma vez que as mudanças socioeconômicas trazem, em especial no capitalismo, na maioria das vezes, uma nova forma de enxergar a realidade, não mais a partir de uma tradição fixa e irredutível (HERVIEU-LÉGER, 2000; 2005).

As identidades7 que antes eram herdadas (HERVIEU-LÉGER, 2008) ganham fluidez e se liquidificam na modernidade. Como já foi dito, a vinda da Petrobrás para cidade de Macaé representa o deslocamento de uma sociedade tradicional para uma sociedade em processo de modernização industrial (ALVARENGA, 2017). Com a modernização da cidade de Macaé a identidade institucional e histórica se tornou menos determinante, fazendo com que o indivíduo tivesse diante de si alternativas de escolhas diante de situações novas e inéditas, que já não necessitam de uma tradição para explicar (ALVARENGA, 2017). Com uma autonomia na esfera simbólica, os indivíduos passaram a buscar algo que correspondesse as suas necessidades individuais, ocorrendo assim um "desencaixe" "entre o preestabelecido, as identidades e as novas religiões que foram surgindo" (HERVIEU-LÉGER, 2008). Pode-se dizer que antes da Petrobrás a prática religiosa dos fieis era mais facilmente definida, haja vista o maior

\footnotetext{
${ }^{7} \mathrm{~A}$ identidade religiosa tanto individual quanto coletiva se constrói na articulação de quatro lógicas, que funcionam em uma tensão proporcional, duas a duas, definindo, assim, os eixos que estruturam o espaço religioso. O primeiro eixo introduz a tensão entre a lógica comunitária que representa o conjunto de marcas sociais e simbólicas que definem as fronteiras do grupo religioso e a lógica ética que consiste no reconhecimento individual de valores ligados à mensagem transmitida pela tradição. $O$ segundo eixo expressa a tensão entre a lógica cultural que reúne o conjunto dos elementos cognitivos, simbólicos e práticos que constituem o patrimônio de uma tradição particular, como doutrinas, livros, revistas de ensino, costumes e outras práticas que se originaram no seio do grupo com a lógica emocional que consiste da experiência afetiva relacionada à identificação, as experiências imediatas e afetivas que por sua vez podem contrapor a memória autorizada do grupo. Quando essas tensões são reguladas pela instituição religiosa ou "poder religioso" o processo de identificação tem continuidade no tempo e no espaço (HERVIEU-LÉGER, 2008; CAMURÇA, 2003).
} 
percentual de igrejas tradicionais neste período, porque herdada das famílias, hoje, o poder de decisão (racionalidade) dos fiéis é outro e com isso as igrejas passaram a regular menos e com pouca influência quanto às escolhas de seus fiéis (HERVIEULÉGER, 2008).

O pluralismo religioso pode ser uma das razões além da inserção em uma nova camada social que fez com que prevalecesse como numa sociedade de mercado o gosto pessoal do "cliente" e as exigências da vida cotidiana em detrimento de um apego a antigas tradições. A religião se tornou uma questão de foro íntimo, da vida privada para os fiéis (HERVIEU-LÉGER, 2008). O pluralismo religioso, constatado a partir do surgimento de novos movimentos religiosos em Macaé, tem atraído os membros das igrejas tradicionais, ocorrendo então um trânsito religioso que não é de somenos importância nesse cenário (SANTOS; ALVARENGA, 2014). Veremos a seguir alguns dados e informações que sustentam os argumentos de enfraquecimento das instituições tradicionais na regulação das crenças, a autonomia na esfera simbólica, o arrefecimento e disputa entre os diferentes campos e a capacidade de se reinventar como fator decisivo para crescimento dos batistas. Na tabela abaixo, é possível visualizar com base nos censos de 1980, 1991, 2000 e 2010 a evolução do crescimento das igrejas de origem pentecostal em relação às igrejas tradicionais.

Tabela 2 - Tradicionais e pentecostais em Macaé

\begin{tabular}{|c|c|c|}
\hline \multicolumn{3}{|c|}{ Tradicionais e Pentecostais em Macaé } \\
\hline & Tradicionais & Pentecostais \\
\hline 1980 & 8,2 & 3,23 \\
\hline 1991 & 8,5 & 5,38 \\
\hline 2000 & 13,06 & 10,32 \\
\hline 2010 & 8,21 & 17,22 \\
\hline
\end{tabular}

Fonte: IBGE - Censos Demográficos 1980, 1991, 2000 e 2010.

O período entre 2000 e 2010 foi crucial para que as igrejas de origem pentecostal ultrapassem as igrejas tradicionais evangélicas em maior número de adeptos. Contudo, a taxa de crescimento é maior entre as igrejas de origem pentecostal do que nas igrejas tradicionais ao longo de todos esses anos. Além do 
fato que entre os anos de 2000 a 2010 as igrejas tradicionais desaceleraram e houve um declínio que se igualou a mesma média entre 1980 e 1991 (ALVARENGA, 2017).

Nessa época poucas igrejas tradicionais experimentaram tamanho crescimento como ocorreu com a Segunda Igreja Batista de Macaé, por sua capacidade de se recompor e se reconfigurar diante de um cenário de enfraquecimento das demais igrejas tradicionais. Isso ocorreu na década de $80 \mathrm{e}$ 90. Nesse período, dois fatores foram importantes para que se desse esse crescimento. O primeiro fator foi o ímpeto evangelístico caracterizado pelas ações estratégicas em campanhas, séries de conferência, programas de rádio e plantação de novas igrejas, voltada, sobretudo, para as pessoas que chagavam na cidade por causa da Petrobrás. O segundo fator aconteceu no final da década de 80 e início da década de 90, quando o então pastor Daniel de Almeida e Souza entendeu que a igreja precisava se reinventar. Para tanto, a liderança lançou mão de alternativas fora do círculo denominacional, como os congressos da Vinde, liderados pelo então pastor presbiteriano Caio Fábio, líder carismático que nesta época atraía membros de várias denominações. Além disso, foi decisiva a adesão da Segunda Igreja Batista de Macaé ao movimento que surgia nesse período no Brasil, que eram os pequenos grupos ou grupos familiares que se reuniam nas casas semanalmente (ALVARENGA, 2017).

Esse movimento teve como inspiração o pastor Paul Young Cho, da Coreia, de linha pentecostal, cujo trabalho rendeu à Igreja do Evangelho Pleno de Yoido, em Seul, o título de maior igreja do mundo, com cerca de 800 mil fiéis. De acordo com depoimento do pastor Daniel Junior, filho do pastor ora citado, esta igreja que chegou a somar dois mil membros, tinha também como característica uma "heterogeneidade" que conseguia reunir diversas correntes teológicas sem gerar divisões, "algo comum na época" (ALVARENGA, 2017). Num primeiro momento, é possível uma análise que considere o fato de que uma nova situação se impôs as igrejas em Macaé e aquelas que não se abriram tiveram um crescimento menor que o esperado (ALVARENGA, 2017). Como é de se esperar, as identidades religiosas 
foram forjadas na medida em que o campo religioso (BOURDIEU, 2003) plural se expandia.

Mesmo filiados a denominações consideradas históricas, cresce cada vez mais o número de "cristãos à sua maneira" (ALVARENGA, 2017). A tendência à individualização e à subjetividade das crenças religiosas é uma realidade que paradoxalmente tem se encaixado no seio das igrejas protestantes de versão histórica. Qualquer política identitária terá que conviver com as identidades políticas. De acordo com Ciampa:

Grupos sociais lutam pela afirmação e pelo desenvolvimento de suas identidades coletivas, no esforço de controlar as condições de vida de seus membros; indivíduos buscam a transformação e o reconhecimento de suas identidades pessoais na tentativa de resolver conflitos em face de expectativas sociais conflitantes. (CIAMPA, 2002, p. 133).

A identidade coletiva não encontra respaldo nas identidades individuais. Esse é o poder de escolha, que antes ele poderia atribuir a uma herança familiar, mas agora ele decide por si só. São indivíduos que fazem valer sua liberdade de escolha, "cada qual retendo para si as práticas e as crenças que lhe convém" (ALVARENGA, 2017). O "significado atribuído a essas crenças e a essas práticas pelos interessados se afasta, geralmente, de sua definição doutrinal" (HERVIEULÉGER, 2008, p. 43). Neste sentido, recorremos a uma metáfora para explicar a questão da identidade religiosa atual. Temos identidades flutuantes cuja característica principal é a complacência e "submersibilidade", e pouca profundidade. São identidades individuais e que algumas vezes se aplica também a coletividade. Também temos as identidades fixas, ilusórias, sob a representação de uma continuidade absolutamente preservada que instaura uma espécie de atemporalidade das verdades fundacionais. São "aquelas apoiadas na tradição e são geralmente aplicadas e defendidas pelas instituições" (CAMURÇA, 2003).

Nesse ambiente sociocultural de grandes mudanças do impacto de empresas (HARVEY, 2005), o processo de individualização da crença não faz desaparecer pura e simplesmente a realidade das identificações confessionais. Mesmo porque 
os campos estão em disputa. Os grupos religiosos lutam cada qual pelo seu capital simbólico (ALVARENGA, 2017). A luta e a constituição de uma identidade de grupo ou coletiva se fazem pela aproximação dos iguais e em certo sentido distanciandose dos diferentes. São parâmetros, são pautas, objetivos que são colocadas de modo distintivo do grupo e qualificativos da experiência e da existência do próprio grupo. Pode-se dizer que a intensificação do pluralismo produziu, devido ao aumento entre os competidores, o reforço das aspirações comunitárias, ao mesmo tempo em que uma certa reativação das identidades confessionais (HERVIEU-LÉGER, 2008). Todavia, como alerta Hervieu-Léger, estas não "coincidem mais necessariamente com identificações religiosas claramente assumidas pelos indivíduos" (HERVIEULÉGER, 2008, p. 52). Cabe aqui dizer que o que ocorre é muito parecido com o que Hervieu-Léger chama de "bricolagem"8 de crenças ou uma identidade híbrida no seio desses grupos religiosos. A identidade denominacional é mais um marketing promocional e demarcador de território, cuja prática na maioria das vezes é heteróclita e incongruente (HERVIEU-LÉGER, 2008).

\section{Conclusão}

O que vimos nesse artigo foi uma análise dos impactos dos processos de produção ligados ao petróleo em uma cidade do interior do estado do Rio de Janeiro, Macaé. Esta, em 40 anos, passou de uma vila esquecida para ser o centro das atenções por concentrar 80\% da produção nacional do petróleo. Para mensurar esses impactos da instalação de empresas de petróleo lançou-se mão de dados quantitativos, dos censos do IBGE de 1980 a 2010, para que fosse possível comparar um antes e depois. Os números mostram que houve impactos indeléveis tanto socioeconômicos, quanto no campo religioso. A religião faz parte da sociedade e não ficaria jamais imune às mudanças que ocorrem em seu seio, mesmo na dinâmica da urbanidade, como escreve Daniele Hervieu-Léger (2005). Esta não precisa ser a única forma de explicar essa realidade, mesmo porque a

\footnotetext{
${ }^{8} \mathrm{O}$ conceito de bricolagem usado por Hervieu-Léger refere-se a crenças “triadas, remanejadas e, geralmente, livremente combinadas a temas emprestados de outras religiões ou correntes de pensamento de caráter místico ou esotérico" (HERVIEU-LÉGER, 2008, p. 43).
} 
religião possui características muito peculiares, não necessariamente pelo sistema de crenças que possui, mas também como "sistemas de regulamentação da vida", cuja capacidade de reunir em torno de si "massas particularmente importantes de fiéis” (HERVIEU-LÉGER, 2008) não está refém unicamente dos fatores econômicos, mas na sociologia da religião de Hervieu-Léger (2005) relaciona-se afetivamente com modulações da urbanidade como o caso do novo arranjo de Macaé.

Além dos números, buscou-se neste trabalho uma interpretação dos mesmos que desse conta da "dinâmica interna" que a estatística por si não explica. Essa é a tarefa da pesquisa, qual seja, a de atribuir sentido aos números e dados. Como se destacou, uma costura com auxílio teórico principalmente de Danièle HervieuLéger (2008) sobre as transformações da religião na modernidade, especificamente as relações da religião com as malhas das cidades (HERVIEU-LEGER, 2005). O pensamento desta autora tem recebido o devido reconhecimento de diversos sociólogos da religião (NOVAES, 2004; ORO, 2003; CAMURÇA, 2003) no Brasil no que se refere a sua capacidade e eficácia para uma compreensão também da realidade latino-americana. Tanto as transformações dos grupos tidos como tradicionais e históricos quanto os sem-religião, além dos novos movimentos religiosos representados pelos (neo) pentecostais, encontram no pensamento de Hervieu-Léger possíveis explicações para o deslocamento do interesse pelas tradições e busca de algo mais subjetivo, onde prevalece uma autonomia em detrimento do que pode vir de cima para baixo, ou seja, de uma instituição religiosa que se pretenda detentora de uma única verdade. 


\section{REFERÊNCIAS}

ALENCAR, Gedeon Freire de. Matriz pentecostal brasileira: assembleias de Deus 1911-2011. Rio de Janeiro: Editora Novos Diálogos, 2013.

ALVARENGA, Leonardo G. Os batistas em movimento: um estudo da dinâmica sócio religiosa de batistas no Brasil: o exemplo de Macaé-RJ. São Paulo, 2017. 260 f. Tese (Doutorado em Ciência da Religião) - Faculdade de Ciências Sociais, Pontifícia Universidade Católica de São Paulo.

ALVARENGA, Leonardo G.; SENA, Daniel Lucas N. Enfoques teóricos sobre religião, urbanidade e memória: experimentos em curso. Observatório da Religião, v. 3, n. 1, p. 92-114, 2016.

ARAÚJO, Faber Paganoto. Migrantes ricos e migrantes pobres: as heranças da economia do petróleo em Macaé. Monografia submetida ao Departamento de Geografia da Universidade Federal do Rio De Janeiro, 2005. Disponível em:

<https://royaltiesdopetroleo.ucam-campos.br/wp-

content/uploads/2017/o5/Monografia_Faber.pdf>. Acesso em: 10 nov. 2018.

BASTIAN, J-P. Le protestantisme en América Latine. Une approche sóciohistorique. Genève: Editions Labor et Fides, 1994.

BEYER, P. Global migration and the selective reimagining of religions. Horizontes antropológicos, Porto Alegre, v. 4, n. 8, 1998.

BOURDIEU, P. O poder simbólico. Rio de Janeiro: Bertrand Brasil, 2003.

BOURDIEU, P. et al. Travail et travailleurs em Algérie. Paris: Mouton, 1963.

BOURDIEU, P. A economia das trocas simbólicas. São Paulo: Perspectiva, 2005.

BRISO, Caio Barretto. A maldição do petróleo. Veja Rio, Rio de Janeiro, 20 jan. 2012. Disponível em: <https://vejario.abril.com.br/cidades/violencia-macae/>. Acesso em: 29 ago. 2016.

CADENA, A.; COSTA, R. C. R. Macaé, capital do petróleo: desenvolvimento econômico, desigualdades sociais e expansão urbana. Uma análise sobre as dimensões renda, educação e saúde, com base nos resultados da pesquisa domiciliar do programa Macaé cidadão 2006-2007. Macaé: Coordenadora Geral do Programa Macaé Cidadão, 2012.

CAMPOS, L. A identidade protestante tradicional: desafios da secularização e do crescimento do pentecostalismo brasileiro. In: DIAS, Zwinglio M. Protestantes, evangélicos e (neo) pentecostais: história, teologias, igrejas e perspectivas. São Paulo: Fonte Editorial, 2013. p. 215-234. 
CAMURÇA, M. A. A sociologia da religião de Danièle Hervieu-Léger: entre a memória e a emoção. In: TEIXEIRA, Faustino (Org.). Sociologia da religião: enfoques teóricos. Petrópolis: Editora Vozes, 2003. p. 249-270.

CHAMPION, Francoise. La nébuleuse mystique-ésotérique. In: CHAMPION, Françoise; HERVIEU-LEGER, Danièle (Org.). De l'émotion en religion. Paris: Éditions du Centurion, 1990. p. 17-68.

CIAMPA, A.C. Políticas de identidade e identidades políticas. In: DUNKER, C. I. L.; PASSOS, M. C. Uma psicologia que se interroga - ensaios. São Paulo: Edicon, 2002. p. 133-144.

DA REDAÇÃO VEJA. Mais de 29 milhões entraram para classe média. Veja, 10 set. 2010. Disponível em: <https://veja.abril.com.br/economia/mais-de-29-milhoes-entraram-paraclasse-media/>. Acesso em: 24 fev. 2016.

FAJARDO, M. P. Pentecostalismo, urbanização e periferia: perspectivas teóricas.

Paralellus, Recife, v. 2, p. 181-192, 2011.

HARVEY, D. A produção capitalista do espaço. São Paulo: Annablume, 2005.

HERCULANO, Selene (Org.). Oficina sobre impactos sociais, ambientais e urbanos das atividades petrolíferas - o caso de Macaé (RJ). Nicho Legal, 12 jan. 2013. Disponível em: <http://www.uff.br/macaeimpacto/oficinamacae/pdf/az_oficinaimpactosmacaetodostext os.pdf $>$. Acesso em: 20 jan. 2013.

HERVIEU-LÈGER, Daniéle. A transmissão religiosa na modernidade: elementos para a construção de um objeto de pesquisa. Estudos de Religião, São Paulo, v. 14, n. 18, p. 3954, 2000.

HERVIEU-LÈGER, Daniéle. La religión, hilo de memoria. Barcelona: Herder Editorial S.L, 2005 .

HERVIEU-LÈGER, Daniéle. O peregrino e o convertido: a religião em movimento. Petrópolis: Vozes, 2008.

IBGE - INSTITUTO BRASILEIRO DE GEOGRAFIA E ESTATÍSTICA. Microdados dos censos demográficos. (1991, 2000, 2010).

IBGE - INSTITUTO BRASILEIRO DE GEOGRAFIA E ESTATÍSTICA. Microdados dos Censos demográficos: Religião, 1980, 1991, 2000 e 2010.

IBGE. Tendências demográficas: uma análise dos resultados da amostra do Censo Demográfico 2000. Informação Demográfica Socioeconômica número 13. 2004. Rio de Janeiro: IBGE. Disponível em: <https://ww2.ibge.gov.br/home/estatistica/populacao/censo200o/default_tendencias.sh tm>. Acesso em: 16 out. 2018. 
JACOB, Cesar Romero et al. Atlas da filiação religiosa e indicadores sociais no

Brasil. Rio de Janeiro: Ed. PUC-Rio; São Paulo: Loyola, 2003.

KNAUSS, P. Macaé: História e memória. Macaé: Fundação Macaé de Cultura, 2001.

LEÃO, Luís Henrique da Costa; GOMEZ, Carlos Minayo. A questão da saúde mental na vigilância em saúde do trabalhador. Ciência \& Saúde Coletiva, Rio de Janeiro, v. 19, n. 12, p. 4649-4658, 2014.

MARINUCCI, Roberto. Reconfiguração da identidade religiosa em contexto migratório. Estudos de Religião, São Paulo, v. 25, n. 41, p. 97-118, jul./dez. 2011.

MARTINE, G. A globalização inacabada migrações internacionais e pobreza do século 21. São Paulo em Perspectiva, São Paulo, v. 19, n. 3, 2005.

MENDONÇA, Antônio Gouvêa; FILHO, Prócoro Velasques. Introdução ao Protestantismo no Brasil. São Paulo: Loyola/ Ciências da Religião, 2. ed. 2002.

MOREIRA, Alberto da Silva. O deslocamento do religioso na sociedade contemporânea. Estudos de Religião, São Paulo, Ano XXII, n. 34, p. 70-83, jan/jun. 2008.

NOVAES, R. Os jovens sem religião: ventos secularizantes, espírito de época e novos sincretismos. Notas preliminares. Estudos Avançados, São Paulo, v. 52, n. 18, p. 321330, 2004.

ORO, A. P. (Org.). Igreja universal do reino de Deus: os novos conquistadores da fé. São Paulo: Paulinas, 2003.

PAGANOTO, F. Mobilidade e trabalho em Macaé/ RJ, a "Capital do petróleo". Rio de Janeiro, 2008. 111 f. Dissertação (Mestrado em Geografia) - Universidade Federal do Rio de Janeiro, 2008.

PIERUCCI, A. F. Secularização e declínio do catolicismo. In: SOUZA, Beatriz Muniz de; MARTINO, Luís Mauro Sá (Org.). Sociologia da religião e mudança social: católicos, protestantes e novos movimentos religiosos no Brasil. São Paulo: Paulus, 2004.

PIQUET, Rosélia. Impactos da indústria do petróleo no Norte Fluminense. In: HERCULANO S. Impactos sociais, ambientais e urbanos das atividades petrolíferas: o caso de Macaé, 2010. Disponével em:

<http://www.uff.br/macaeimpacto/OFICINAMACAE/apresentacoes16.html>. Acesso em: 22 mar. 2017.

PY, F. Lauro Bretones, um protestante heterodoxo no Brasil de 1948 a 1956. Rio de Janeiro, 2016a. 258 f. Tese (Doutorado em Teologia) - Departamento de Teologia, Pontifícia Universidade Católica do Rio de Janeiro.

PY, Fábio. Lutheran rebellion in the Brazilian countryside. Cross Currents, Chicago, v. 66, p. 252-266, 2016b. 
PY, Fábio; PEDLOWSI, M. A. Atuação de religiosos luteranos nos movimentos sociais rurais do Brasil de 1975 a 1985. Tempo, Niterói, v. 24, n. 2, p. 233-252, 2018.

ROLIM, F. C. Pentecostais no Brasil: uma interpretação sócio-religiosa. Rio de Janeiro: Vozes, 1979.

SANTOS, A. F. P. R.; ALVARENGA, L.G. O lugar social da igreja: um estudo da relevância social de duas igrejas evangélicas históricas em dois bairros pobres do município de Macaé/RJ. $27^{\circ}$ Congresso Internacional Sociedade de Teologia e Ciências da Religião, Belo Horizonte, p. 121-134, 2014.

SILVA, S. R. A.; FARIA, T. J. P. O mapa da migração em Macaé: impactos da industrialização no processo de urbanização. 2016. Disponível em:

<http://periodicos.ufes.br/SNPGCS/article/view/1577>. Acesso em: 17 mar. 2016.

STARK, R.; BAINBRIDGE, W. S. Uma teoria da religião. São Paulo: Paulinas, 2008.

SWATOWISKI, C. W. Dinâmicas espaciais em Macaé: lugares públicos e ambientes religiosos. In: ALMEIDA, R; MAFRA, Clara (Org.). Religiões e cidades: Rio de Janeiro e São Paulo. São Paulo: Editora Terceiro Nome, 2009. p. 51-68.

SWATOWISKI, C. W. Igreja universal na capital nacional do petróleo: uma etnografia sobre as dinâmicas da comunicação de massa a serviço de Deus. Rio de Janeiro: PPCIS; UERJ, 2009.

TEIXEIRA, F. Apresentação. In: HERVIEU-LÈGER, D. O peregrino e o convertido: a religião em movimento. Petrópolis: Vozes, 2008.

TEIXEIRA, F.; MENEZES, R. (Org.). Religiões em movimento: o censo de 2010. Petrópolis: Vozes, 2013. 